\title{
Strangulated Spiegel's hernia mimicking ischaemic colitis: endoscopic diagnosis of a rare surgical emergency
}

\author{
Tiago Cúrdia Gonçalves, ${ }^{1,2}$ Sara Monteiro, ${ }^{1,2}$ Carla Marinho, ${ }^{1,2}$ José Cotter $^{1,2}$
}

${ }^{1}$ Gastroenterology Department, Hospital da Senhora da Oliveira, Guimarães, Portugal

${ }^{2}$ Life and Health Sciences Research Institute, School of Medicine, University of Minho, Braga, Portugal

\section{Correspondence to}

Dr Tiago Cúrdia Gonçalves, tiagomcg@hotmail.com

Accepted 9 January 2018

\section{DESCRIPTION}

An 84-year-old man was referred to the emergency department with a 2-day history of colicky abdominal pain in the left lower quadrant, bloody diarrhoea and abdominal distension. Nausea and two episodes of watery vomiting were reported as well. Past medical history was remarkable for arterial hypertension, dyslipidaemia and ischaemic stroke, for which he was taking lisinopril, hydrochlorothiazide, simvastatin and acetylsalicylic acid. Surgical background included laparotomy for appendectomy and appendicular abscess drainage 8 years before.

Physical examination showed stable vital signs and a distended abdomen, with tenderness in the left lower abdominal quadrant, but no signs of peritoneal irritation. An obvious, but reducible, abdominal wall hernia was palpable in the same location. The remaining exam was unremarkable.

Laboratory results revealed mild anaemia (haemoglobin-12.7 g/dL) and leukocytosis (white cell count- $11.7 \times 10^{9} / \mathrm{L}$ ), acute kidney injury (creatinine-2.1 mg/dL) and elevated $C$ reactive protein $(298 \mathrm{mg} / \mathrm{L})$. Liver function tests, electrolyte panel, amylase and lactate dehydrogenase were within the normal range.

An abdominal CT scan showed thickening of the descending colon wall and a left-side Spiegel's hernia with epiploic fat and a segment of the descending colon protruding through the hernia orifice (figure 1). However, as the patient had a reducible hernia at physical examination, he was admitted to the ward with the suspicion of ischaemic colitis and put under bowel rest, intravenous

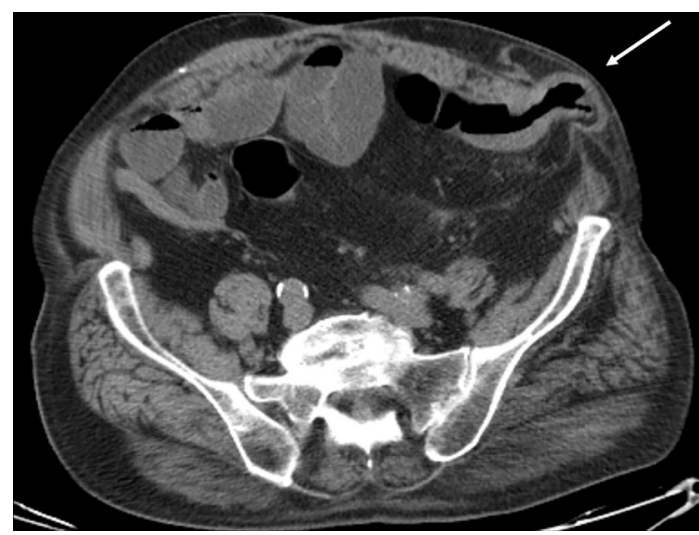

Figure 1 Abdominal CT scan. Left-side Spiegel's hernia with epiploic fat and a segment of the descending colon protruding through the hernia orifice (white arrow).

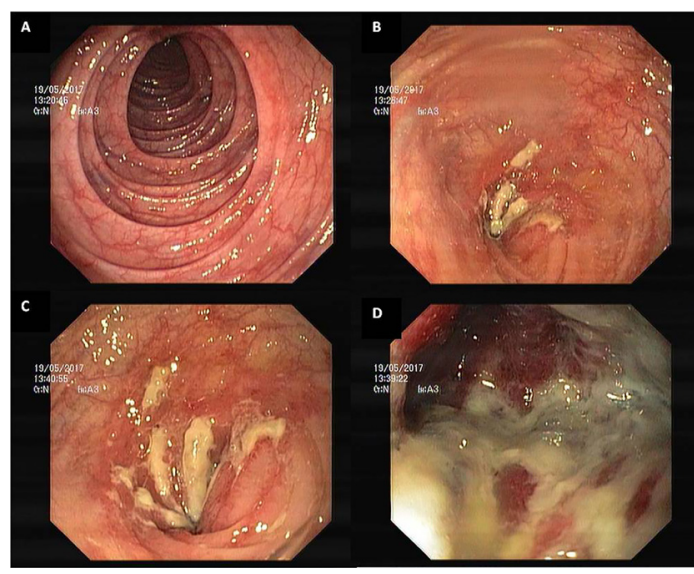

Figure 2 Flexible sigmoidoscopy. (A) Normal mucosa in the distal sigmoid colon. (B) Luminal constriction in the proximal sigmoid colon. (C) Congestive and fibrin-covered mucosa. (D) Oedematous, violaceous, fibrin-covered mucosa.

hydration and antibiotic therapy with metronidazole and ciprofloxacin.

A flexible sigmoidoscopy was performed 48 hours after admission for confirmation of the suspected diagnosis of ischaemic colitis. Endoscopic evaluation revealed an abrupt transition from normal colonic mucosa to a markedly oedematous, violaceous, fibrin-covered mucosa within an area of decreased luminal calibre (figure 2). Abdominal transillumination was noted in the left lower abdominal quadrant at the limit of scope's progression, and a diagnosis of incarcerated Spiegel's hernia was confirmed.

The patient was submitted to an urgent laparotomy, in which an extensive segment of colonic necrosis (from splenic flexure to proximal sigmoid colon) without perforation was identified. After segmental colectomy of the unviable colon, an end colostomy was performed. The patient recovered uneventfully and was discharged 10 days after surgery.

Spiegel's hernias are very uncommon and are estimated to account for $0.12 \%$ of all abdominal wall hernias. ${ }^{1}$ They occur through defects in the anterior abdominal wall adjacent to the semilunar line, frequently in the lower abdomen. ${ }^{2}$ In many cases, the diagnosis of Spigelian hernia is not straightforward because the external oblique muscle overlies the defect in the deeper fascia and also symptoms can vary from abdominal pain, a lump in the anterior abdominal wall or signs of bowel obstruction. ${ }^{2}$ While incarceration or strangulation of Spiegel's 
hernias can occur in up to $24 \%$ of the cases, sonography and CT scan are the most commonly used adjuncts for the diagnosis. ${ }^{3}$ Endoscopic examinations are not generally used in this context but are a valuable and recommended tool to confirm the suspicion of colonic ischaemia. To the best of our knowledge, this is

\section{Learning points}

- Although rare, Spiegel's hernias should be considered in the differential diagnosis of abdominal pain, especially when a lump in the abdominal wall is palpated during the physical examination.

- Incarceration or strangulation of a Spiegel's hernia can occur in almost a quarter of the patients, thus specific manifestations of these complications should be sought.

- Strangulated Spiegel's hernia may present with abdominal pain and bloody diarrhoea mimicking ischaemic colitis, a distinction that may be particularly difficult when several vascular risk factors are present. the first case report of a strangulated Spiegel's hernia diagnosed by colonoscopy.

Contributors All authors have contributed to and agreed on the content of the manuscript. TCG was involved in the patient's management, did the literature research and drafted the manuscript; SM was involved in the patient's management, $\mathrm{CM}$ revised the manuscript and JC critically revised the manuscript and approved the final version to be submitted.

Funding This research received no specific grant from any funding agency in the public, commercial or not-for-profit sectors.

Competing interests None declared.

Patient consent Obtained.

Provenance and peer review Not commissioned; externally peer reviewed.

(c) BMJ Publishing Group Ltd (unless otherwise stated in the text of the article) 2018. All rights reserved. No commercial use is permitted unless otherwise expressly granted.

\section{REFERENCES}

1 Houlihan TJ. A review of Spigelian hernias. Am J Surg 1976;131:734-5.

2 John RJ, Ulahannan SE, Kurien JS, et al. Rare Hernias Presenting as Acute Abdomen- A Case Series. J Clin Diagn Res 2016;10:PR01-4.

3 Nagarsheth KH, Nickloes T, Mancini G, et al. Laparoscopic repair of incidentally found Spigelian hernia. JSLS 2011;15:81-5.

Copyright 2017 BMJ Publishing Group. All rights reserved. For permission to reuse any of this content visit http://group.bmj.com/group/rights-licensing/permissions.

BMJ Case Report Fellows may re-use this article for personal use and teaching without any further permission.

Become a Fellow of BMJ Case Reports today and you can:

- Submit as many cases as you like

- Enjoy fast sympathetic peer review and rapid publication of accepted articles

- Access all the published articles

- Re-use any of the published material for personal use and teaching without further permission

For information on Institutional Fellowships contact consortiasales@bmjgroup.com

Visit casereports.bmj.com for more articles like this and to become a Fellow 